The author has confined himself strictly to common skin diseases and has accordingly produced a handbook of great value to students and general practitioners. It is noted, however, that this edition has been slightly enlarged by the addition of several conditions omitted from the first. This we look on as a sign of robust health in this small book, and we hope that in subsequent editions it will continue to grow until it eventually reaches adult status in the form of a textbook of dermatology, for the author has a clear style of writing and presents his facts in an eminently practical manner which is well suited to the production of a larger book on the subject.

$$
\text { P. A. M. }
$$

THE PRINCIPLES AND PRACTICE OF NEUROLOGY. -By A. Cannon, K.C.A., M.D., Ph.D., D.P.M., R.C.P.S. (Lond.), and E. D. T. Hayes, M.D., D.P.M., R.C.P. \&S. (Lond.). 1934. William Heinemann (Medical Books) Limited, London. Pp. $x x$ plus 333 . Illustrated. Price, 25s.

THE 'Principles and Practice of Neurology' is an important and comprehensive work by several authors. Within the scope of 325 pages is collected an abundance of facts welded together with much skill into a well-balanced whole. The reader is most impressed by the mature judgment displayed by the authors. All the modern advances in knowledge on this subject have been carefully incorporated, and throughout there is the mark of great ability and a wide personal experience, which together with the literary quality of writing maintains the readers' interest.

The first -55 pages are devoted to clinical examination of the nervous system by Professor G. H. Monrad Krohu. In the next 270 pages follows a description of various nervous diseases dealt with systematically from the point of view of rtiology, signs and symptoms, prognosis, course and treatment. The section on cerebral tumours could hardly be improved on in the allotted space. The description of the inflammatory diseases of the nervous system, pyogenic and nonpyogenic, is conspicuously full. The section on rare diseases showing neurological signs and symptoms is a very valuable addition.

This book should be read not only by neurologists but by general medical practitioners as well. As the book is meant by its authors to be of special value to students of psychology the psychiatric aspect of certain diseases has received rather detailed attention. The book is not over-burdened with illustrations which is an advantage, while those given are very helpful. The paper and printing are both excellent

and it well deserves the reception accorded to it.
R. N. C.

AIDS TO PSYCHIATRY - By W. S. Dawson, M.A., M.D. (Oxon.), F.R.C.P. (Lond.), D.P.M. Third Edition. 1934. Baillière, Tindall and Cox, London.

Pp. vii plus 318. Price, 4s. 6d.

This little book has now passed into its third edition. As the author states in his preface to this edition, several sections have been rewritten and recent changes in the lunacy laws have received appropriate notice. Special sections are devoted to legal procedure in Scotland. One may deplore the somewhat inadequate treatment still accorded to convulsive seizures, especially in children, in view of the fact that the book is written partly to help the general practitioner. There are not many topics in general medicine on which the general practitioner is in greater need of instruction than the correct diagnosis and prognosis of 'fits' in children. Hence some reference to the work of Ewald Stier of Berlin, as well as to that of others, should at least have been made. Similarly, no mention is made of the important researches of Pavlov and Lashley, researches that seem likely to add very materially to our knowledge of the organic basis of mind. The author dismisses in a few words the subject of the psycho-analysis of children thereby leaving the reader that is not acquainted with psycho-analysis in general with the impression that the psycho-analysis of children is a procedure identical with that of adults, when, as a matter of fact, the technique is wholly different. The reference to Dr. Morton Prince on page 275 might lead the reader to suppose that this eminent American psychiatrist is still living; very unfortunately for psychiatry he died some years ago. In spite of these minor defects the book is well adapted for either the medical student or for those who seek the Diploma of Psychological Medicine or other kindred degree.

\section{O. B.-H}

\section{HYPNOTISM IN THE TREATMENT OF DISEASES.-}

By B. Layton Lloyd, M.B., D.P.H. 1934. John Bale, Sons and Danielsson, Limited, London. Pp. vil plus 44 . Price, 3s. 6d.

Is this small booklet the author has put forward his reasons for the more extensive use of hypnotism in the treatment of diseases, particularly functional in origin, and in which emotions and psychical factors play the chief part. He goes so far as to say that he is able to produce deep hypnosis and a stage of anæsthesia. Under its influence he is able to perform operations such as opening of deep abscesses, extraction of teeth and even deep operations. By hypnotism he is able to differentiate between functional and organic disorders, since a functional disorder disappears after one or two séances. The other diseases which can according to him be cured are paralysis, blindness, aphasia, amnesia, stammering, pain, pruritis, skin diseases, asthma, addiction habits, etc.

He suggests that research into the art of hypnotism will bring about a closer relationship between physiology and pharmacology more than the laboratory experiments have done. The basis of hypnotism treatment is that it influences the internal secretions of hormones and produces strong suggestions on the subconscious mind. Hypnotism is a very potent medium of treatment and therefore should be used more extensively in practice.

Whether one can accept all the assertions made by the author or not the book undoubtedly is interesting and is written in very simple and clear English. It would have been to the advantage of practitioners if the author had included a chapter on the practical methods of inducing hypnosis by hypnotic suggestion.

R. N. C.

Note.-We have been asked to publish the following note in regard to this book.-EDitor, I. M. G. :-

\section{Correction}

The statement on page 34 to the effect that a patient had eleven teeth filled at one sitting, under posthypnotic anæsthesia, is not correct. I endeavoured to get in touch with the dentist before publication, but was not able to do so.

The dentist now confirms the statement that the anæsthesia was perfect, and that several fillings were below the margin of the gums, but adds that the fillings were done at several sittings.

This does not affect the principle; in fact it is a severer test for the patient to be able to go several times and get immediate and complete anæsthesia every time, than it would be if it only occurred once.

It is not easy to account for the patient's lack of precise knowledge; he knew he went several times, but thought the other visits were for scaling.

I can only assume that the anæsthesia was so complete that he could not tell what was being done.

This is the only statement of observed fact mentioned in the book which did not come under my personal supervision (I was present at the extractions), and although it does not alter the value of posthypnotic anæsthesia, I am correcting this error at the 